\title{
Photoinduced electron transfer across linearly fused oligo-norbornyl structures
}

\author{
Tahsin J. Chow, ${ }^{\mathrm{a}, *}$ Yan-Ting Pan, ${ }^{\mathrm{b}}$ Yu-Shan Yeh, ${ }^{\mathrm{b}}$ Yuh-Sheng Wen, ${ }^{\mathrm{a}}$ Kew-Yu Chen ${ }^{\mathrm{b}}$ \\ and Pi-Tai Chou ${ }^{\mathrm{b}}$ \\ anstitute of Chemistry, Academia Sinica, Taipei 115, Taiwan, ROC \\ ${ }^{\mathrm{b}}$ Department of Chemistry, National Taiwan University, Taipei 106, Taiwan, ROC
}

Received 28 March 2005; revised 9 May 2005; accepted 11 May 2005

Available online 4 June 2005

\begin{abstract}
The rates of photoinduced electron transfer (ET) reactions across two oligo-norbornyl spacer groups (S), that is, structure 1 fused by two norbornadiene (NBD) units and structure 2 fused by three NBD units, are examined. Substituted naphthalene acted as an electron donor (D), whilst ethylene-1,2-dicarboxylate as an electron acceptor (A). ET rates were measured by fluorescence quenching experiments on these D-S-A dyads, and the results were correlated with reaction free energies according to the Marcus relationship. It was found that naphthalene with phenyl substituents showed relatively slower ET rates. The conformational flexibility of phenyl substituents may cause a hindrance on the electronic coupling between D and A. Another salient feature was the abnormally high quenching rates observed in nonpolar solvents such as cyclohexane, the results of which may be ascribed to a competing energy transfer process.
\end{abstract}

(C) 2005 Elsevier Ltd. All rights reserved.

\section{Introduction}

Electron transfer process occurs ubiquitously in many physical and biological pathways, and the fundamental and applications of which have received much attention. Recent advances in this field have extended to the design of molecular devices, in which donor (D) and acceptor (A) pairs are ingeniously linked by covalent spacers $(S)$ to form D-S-A dyads. Electron transfers between D and A across S in a controlled manner may thus, display useful functionalities such as molecular rectifiers, ${ }^{1}$ switches, ${ }^{2}$ electrochemical sensors, ${ }^{3}$ photovoltaic cells, ${ }^{4}$ and nonlinear optical materials, ${ }^{5}$ etc. Spacer groups that have been utilized are versatile, including small molecules, for example, cyclohexane, ${ }^{6}$ adamantane, ${ }^{7}$ bicyclo[2.2.2] octane, ${ }^{8}$ steroids, ${ }^{9}$ and oligomers of various sizes, for example, polynorbornanes, ${ }^{10}$ and ladderanes, ${ }^{11}$ etc. Among numerous types of spacers, rigid linear rod-shaped structures, however, are not commonly seen. ${ }^{12,13}$ The highly symmetrical structures reduce the complexity due to the constraint of geometrical and conformational variations. In our previous studies on photoinduced electron transfer (ET) reactions, the rates of ET in two series of oligo-norbornyl (NB) derivatives (1 and 2) have been estimated. ${ }^{14}$ The geometry of these compounds

Keywords: Electron transfer; Donor and acceptor; Poly-norbornyl; Marcus relationship; Charge transfer.

* Corresponding author. Tel.: +886 2 27898552; fax: +886 227884179; e-mail: tjchow@chem.sinica.edu.tw has the virtue of high symmetry as well as structural rigidity, so that the D and A chromophores can be aligned linearly across a $\sigma$-skeleton. The distance between the centers of $\mathrm{D}$ and $\mathrm{A}$ in compounds $\mathbf{1}$ and $\mathbf{2}$ is then adjustable by the number of NB units. Their ET rates were found to correlate well with both D-A distance and solvent polarities. For example, varying the D-A distance from $1\left(5.5 \times 10^{9} \mathrm{~s}^{-1}\right.$ for $5 \mathbf{a}$ in diethyl ether) to $2\left(5.4 \times 10^{7} \mathrm{~s}^{-1}\right.$ for $\left.7 \mathbf{a}\right)$ reduced the ET rates by approximately two orders of magnitude. A $\beta$ value of 0.77 was estimated according to an exponential decay relationship expressed in Eq. 6 (vide infra). The value of electronic coupling element $H_{\mathrm{el}}$ can further be deduced, which was found to be a function of $\mathrm{D}-\mathrm{A}$ orientation and the bonding nature of the spacer. Such information is valuable for the future design of molecular devices utilizing these spacer groups. In this report, a comprehensive work based on the design and synthesis of analogues of compound $\mathbf{1}$ and 2 was performed to shed light on their associated ET dynamics. Consequently, the mechanism of photoinduced ET process is rigorously examined.

\section{Results and discussion}

\subsection{Compounds preparation and characterization}

Compounds $\mathbf{1}$ and $\mathbf{2}$ were prepared through a coupling reaction of norbornadiene (NBD) catalyzes by 
$\mathrm{Co}_{2}(\mathrm{CO})_{6}\left(\mathrm{PPh}_{3}\right){ }^{15}$ The naphthalene donor (D) groups of $\mathbf{4 a - c}$ and $\mathbf{6 a - c}$ were fused on by [4+2] cycloaddition of respective $o$-quinodimethane derivatives. ${ }^{16}$ The two orthobromo substituents of $\mathbf{4 b}$ and $\mathbf{6 b}$ were transformed to the phenyl groups of $\mathbf{4 d}$ and $\mathbf{6 d}$ by Suzuki coupling reaction using $\mathrm{PhB}(\mathrm{OH})_{2}$ and $\mathrm{Pd}\left(\mathrm{PPh}_{3}\right)_{4}{ }^{17}$ The dicarboxylate acceptor (A) groups of $\mathbf{5 a}-\mathbf{d}$ and $7 \mathbf{a}-\mathbf{d}$ were made by $[2+2]$ cycloaddition reactions with dimethyl acetylenedicarboxylate (DMAD) upon the catalysis of $\mathrm{RuH}_{2}$ $(\mathrm{CO})\left(\mathrm{PPh}_{3}\right)_{3} \cdot{ }^{18}$ All compounds exhibited two-fold symmetry on NMR spectral signals.

$\mathrm{X}$-ray diffraction analysis on a single crystal of $\mathbf{5 c}$ was performed. An ORTEP drawing of the structure is shown in Figure 1. It appears that the central skeleton of $(\mathrm{NBD})_{2}$ is zig-zag in shape. The special orientation between D and A attached onto spacer 1 (i.e., 5a-c) is slightly different from that attached onto spacer $2(\mathbf{7 a}-\mathbf{c})$. For example, structure of $\mathbf{5 c}$ consists of both $\mathrm{D}$ and A groups locked rigidly via the spacer (S), forming a dihedral angle of ca. $110^{\circ}$. The estimated centerto-center distance was $10.9 \AA$ from the central bond of naphthalene to the middle of the line connecting the two carbonyl groups. In the homologous compound $7 \mathbf{c}$, the D-A

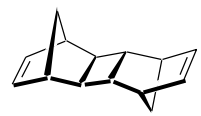

1

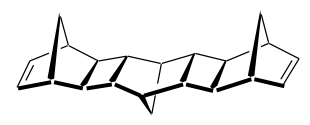

2

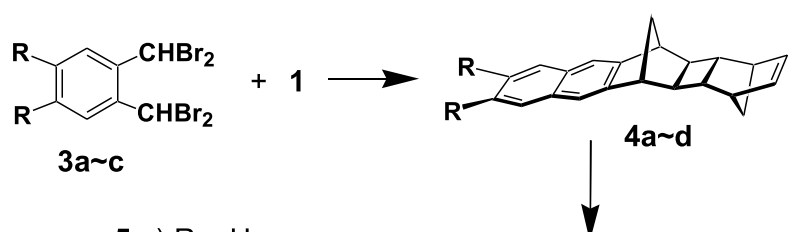

5 a) $\mathrm{R}=\mathrm{H}$

b) $\mathrm{R}=\mathrm{Br}$

c) $\mathrm{R}=\mathrm{OCH}_{3}$

d) $\mathrm{R}=\mathrm{Ph}$

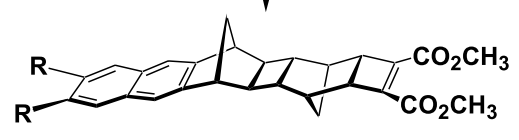

6a d

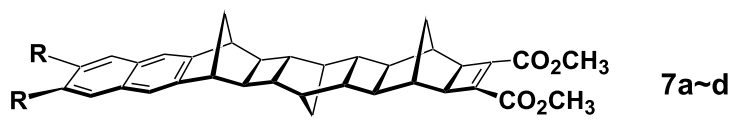

distance was estimated to be $14.7 \AA$. The $\pi$-faces of D and A were aligned parallel to each other, yet not on the same plane.

\subsection{Spectroscopic property}

Figure 2 depicts the absorption and emission spectra of two prototypical models $\mathbf{4 c}$ and $\mathbf{4 d}$, in which $\mathbf{4 c}$ consists of two major absorption bands on the long wavelength side of the UV spectra. The one at $300-320 \mathrm{~nm}$, corresponding to the first $\left(\pi, \pi^{*}\right)$ transition of naphthalene moiety, is assigned to the ${ }^{1} \mathrm{~A} \rightarrow{ }^{1} \mathrm{~L}_{\mathrm{b}}$ transition according to the Platt classification, ${ }^{19}$ whereas the next higher level transition at 245 $290 \mathrm{~nm}$ is assigned to the ${ }^{1} \mathrm{~A} \rightarrow{ }^{1} \mathrm{~L}_{\mathrm{a}}$ transition (Fig. 2). Both bands exhibit distinctive vibronic progressions as a result of conformation rigidity. Excitation at $310 \mathrm{~nm}$ induced a fluorescence at $320-380 \mathrm{~nm}$. The high-energy edge of the emission spectrum overlaps well with $0-0$ band of absorption. The nearly negligible amount of Stokes' shift reflects a high structural similarity between the ground and excited states. Similar spectral features also appeared on $\mathbf{4 a}$ and $\mathbf{4 b}$.

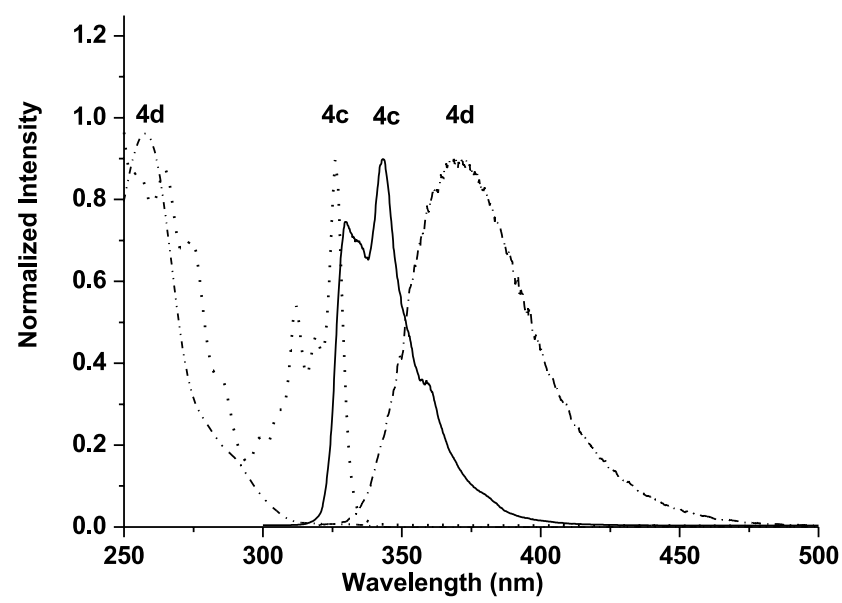

Figure 2. Absorption and emission spectra of compounds $\mathbf{4 c}$ and $\mathbf{4 d}$ in $\mathrm{CH}_{3} \mathrm{CN}$.

In a sharp contrast, the UV spectra of diphenyl substituted derivatives $\mathbf{4 d}-\mathbf{7 d}$ exhibit a quite different pattern. The major absorption band of $\mathbf{4 d}$ is broad with a peak wavelength at $258 \mathrm{~nm}\left({ }^{1} \mathrm{~B}_{\mathrm{b}}\right.$ band), accompanied by a

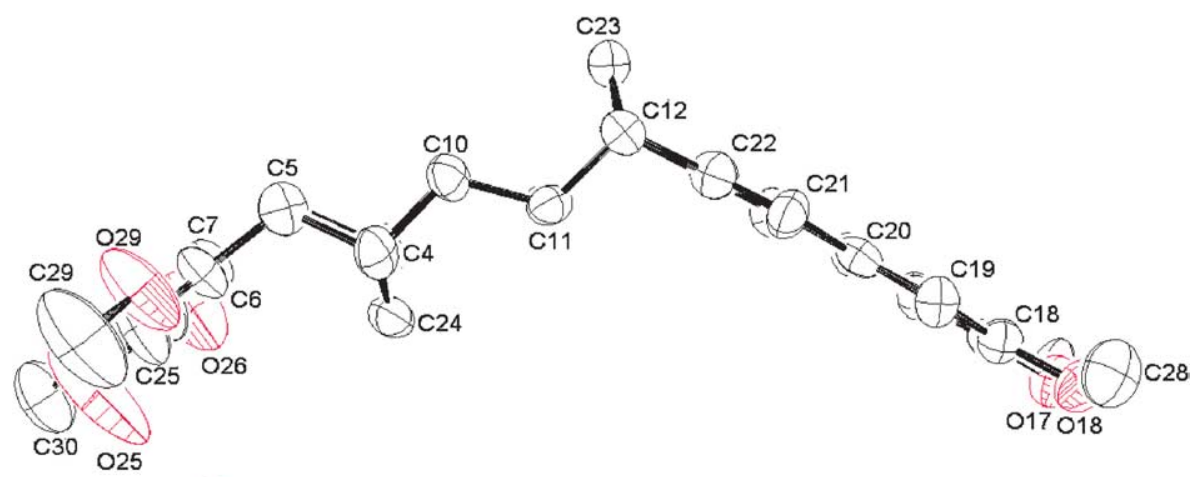

Figure 1. Molecular structure of compound $\mathbf{5 c}$ in single crystal. 
shoulder at $\sim 280 \mathrm{~nm}\left({ }^{1} \mathrm{~L}_{\mathrm{a}}\right.$ band). The $\mathrm{S}_{1}$ transition $\left({ }^{1} \mathrm{~L}_{\mathrm{b}}\right.$ band) appears in low intensity at $310-335 \mathrm{~nm}$ (Fig. 2). It is well understood that phenyl substituents at C-2 position shift the ${ }^{1} \mathrm{~L}_{\mathrm{b}}$ band bathochromically because of its longitudinal polarization. ${ }^{20}$ The broad and featureless shape is apparently caused by the rotational flexibility of the phenyl groups. The fluorescence spectrum of $\mathbf{4 d}\left(\lambda_{\max }\right.$ at $370 \mathrm{~nm})$ exhibited a substantial red-shift $(37 \mathrm{~nm})$ and wider full width at half maximum (fwhm $\sim 56 \mathrm{~nm}$ ) comparing to that of $4 \mathbf{c}\left(\lambda_{\max } \sim 343 \mathrm{~nm}\right.$, fwhm $\left.\sim 26 \mathrm{~nm}\right)$. The broadening of emission band in $\mathbf{4 c}$ indicates either a significant mixing between phenyl $\pi$-orbitals and naphthalene chromophore or, in part, the diphenyl conformational flexibility.

\subsection{Electron transfer kinetics}

The oxidation potentials of naphthalene moieties were measured by cyclic voltammetry (see Table 1 ). The values obtained for $\mathbf{5 a}-\mathbf{c}$ agreed with the substituent effect, for example, $1.27 \mathrm{~V}$ for $\mathbf{5 c}(\mathrm{di}-\mathrm{MeO})$ and $1.78 \mathrm{~V}$ for $\mathbf{5 b}(\mathrm{di}-\mathrm{Br})$. The reduction potential of ethylene-1,2-dicarboxylate moiety was estimated to be $-1.57 \mathrm{~V}$. These values were used for evaluating the free-energy $(\Delta G)$ of ET between an excited-state donor molecule $\left(D^{*}\right)$ and a ground-state acceptor at a defined distance $(d)$ according to Eq. 1: ${ }^{21}$

$$
\begin{aligned}
\Delta G(d)= & E_{\mathrm{ox}}(\mathrm{D})-E_{\mathrm{red}}(\mathrm{A})-E_{00}(\mathrm{D})-\left(e^{2} / \varepsilon d\right) \\
& -\left(e^{2} / 2\right)\left(1 / r_{\mathrm{D}}^{+}+1 / r_{\mathrm{A}}^{-}\right)(1 / 37-1 / \varepsilon)
\end{aligned}
$$

Table 1. The oxidation potentials and $0-0$ band of absorptions

\begin{tabular}{lcccc}
\hline & $\mathbf{5 a} / \mathbf{7 a}$ & $\mathbf{5 b} / \mathbf{7 b}$ & $\mathbf{5 c / 7} \mathbf{c}$ & $\mathbf{5 d} / \mathbf{7 d}$ \\
\hline $\mathrm{E}_{\mathrm{OX}}(\mathrm{eV})$ & 1.74 & 1.78 & 1.27 & 1.50 \\
$E_{00}(\mathrm{~nm})$ & 317 & 330 & 326 & 335 \\
\hline
\end{tabular}

where $E_{\mathrm{ox}}(\mathrm{D})$ and $E_{\text {red }}(\mathrm{A})$ are the oxidation and reduction potentials of $\mathrm{D}$ and $\mathrm{A}$ molecules, respectively, in acetonitrile. $E_{00}(\mathrm{D})$ is the energy of $0-0$ transition, $r_{\mathrm{D}}^{+}$and $r_{\mathrm{A}}^{-}$are effective ionic radii, $\varepsilon$ is the dielectric constant of solvent, and $d$ is the center-to-center distance between $\mathrm{D}$ and $\mathrm{A}$. An approximation was further, made on $r=r_{\mathrm{D}}^{+}=r_{\mathrm{A}}^{-}=4.5 \AA^{22}$ With all of the values substituted into Eq. 1, the free energies were calculated and listed in Table 2. Figure 3 shows a linear plot of $\Delta G$ versus $1 / \varepsilon$. Obviously, the ET processes are calculated to be exothermic in most solvents, except in a few nonpolar media such as $n$-hexane.

The rates of ET were estimated by Stern-Volmer relationship expressed as $k_{\mathrm{ET}}=\left[\left(\Phi_{\mathrm{rel}}-1\right) / \Phi_{\mathrm{rel}}\right]\left(1 / \tau_{\mathrm{D}}\right)$; where $\Phi_{\text {rel }}$ is the relative fluorescence intensity of $\mathrm{D}-\mathrm{S}-\mathrm{A}$ dyads molecules $\mathbf{5}$ and $\mathbf{7}$ with respect to those of standards $\mathbf{4}$ and 6, while $\tau_{\mathrm{D}}$ is the fluorescence lifetime of the latter. The measurements were performed in five different solvents in order to examine the effect of solvent and the results are listed in Table 2. Note that data relevant to compounds $\mathbf{5 a} / \mathbf{4 a}$ and $7 \mathbf{a} / \mathbf{6 a}$ were extracted from our previous report. ${ }^{14}$ As supported by Table 2, it was apparent that the ET rates increase upon decreasing the values of $\Delta G$.

Theoretically, upon excitation electron migrates (or tunnels) from donor to acceptor site via the spacer, forming a chargeseparated ion pair. Charge recombination to the ground state may result in a low energy emission as the charge-transfer band (CT band). Our previous analyses have shown that the decaying rate of fluorescence coincides with the rising dynamics of the CT band. In many cases, however, the CT band may not be readily detected due to its weak intensity, particularly in high polarity solvents such as acetonitrile, in which the lower energy emission is subject to dominant radiationless deactivation described by an energy gap law. ${ }^{23}$ As shown in Figure 4, in contrast to a unique normal fluorescence for $\mathbf{4 d}$ in THF, dual emission was observed in 5d, in which a broad CT band centered at $\sim 500 \mathrm{~nm}$ was resolved. CT emissions in other solvents such as dichloromethane and ethyl acetate can also be detected, yet in very

Table 2. Free energies $(\Delta G)$, relative luminescence quantum yields $\left(\Phi_{\mathrm{rel}}\right)$ and $k_{\mathrm{ET}}$ of electron transfer reactions for the dipolar compounds 4-7 in various

\begin{tabular}{|c|c|c|c|c|c|c|c|c|c|c|c|c|}
\hline Solvent & $\tau(\mathrm{ns})$ & $\Delta G(\mathrm{eV})$ & $\Phi_{\text {rel }}$ & $\begin{array}{c}k_{\mathrm{ET}} \\
\left(\times 10^{8} \mathrm{~s}^{-1}\right)\end{array}$ & $\frac{H_{\mathrm{el}}}{\left(\mathrm{cm}^{-1}\right)}$ & $\tau(\mathrm{ns})$ & $\Delta G(\mathrm{eV})$ & $\Phi_{\text {rel }}$ & $\begin{array}{c}k_{\mathrm{ET}} \\
\left(\times 10^{8} \mathrm{~s}^{-1}\right)\end{array}$ & $\frac{H_{\mathrm{el}}}{\left(\mathrm{cm}^{-1}\right)}$ & $\beta^{\prime}$ & $\beta$ \\
\hline & $4 a^{a}$ & $5 a$ & $5 a / 4 a^{b}$ & $5 \mathbf{a}$ & $5 \mathbf{a}$ & $6 a^{a}$ & $7 \mathbf{a}$ & $7 a / 6 a^{b}$ & $7 \mathbf{a}$ & $7 \mathbf{a}$ & $7 \mathbf{a} / \mathbf{5 a}$ & $7 \mathbf{a} / \mathbf{5 a}$ \\
\hline $\mathrm{Et}_{2} \mathrm{O}$ & 41 & -0.25 & 0.044 & 55 & 1.2 & 57 & -0.17 & 0.247 & 0.54 & 0.046 & 0.77 & 1.01 \\
\hline EtOAc & 61 & -0.37 & 0.020 & 83 & 1.8 & 51 & -0.32 & 0.163 & 1.01 & 0.097 & 0.73 & 0.97 \\
\hline $\mathrm{THF}$ & 58 & -0.44 & 0.017 & 100 & 2.3 & 57 & -0.39 & 0.012 & 1.3 & 0.125 & 0.72 & 0.97 \\
\hline \multirow[t]{2}{*}{$\mathrm{CH}_{2} \mathrm{Cl}_{2}$} & 37 & -0.48 & 0.023 & 120 & 2.6 & 48 & -0.44 & 0.047 & 4.2 & 0.25 & 0.56 & 0.78 \\
\hline & $4 c^{a}$ & $5 c$ & $5 c / 4 c$ & $5 c$ & $5 c$ & $6 c$ & $7 c$ & $7 c / 6 c$ & 7c & $7 c$ & $7 c / 5 c$ & $7 c / 5 c$ \\
\hline $\mathrm{C}_{6} \mathrm{H}_{12}$ & 6.84 & -0.12 & 0.104 & 13 & - & 11 & 0.05 & 0.64 & 0.51 & - & 0.54 & - \\
\hline EtOAc & 5.96 & -0.74 & 0.0068 & 246 & 9.1 & 12 & -0.68 & 0.35 & 1.55 & 0.58 & 0.84 & 0.92 \\
\hline $\mathrm{THF}$ & 6.78 & -0.80 & 0.0124 & 117 & 6.4 & 12 & -0.75 & 0.22 & 2.95 & 0.82 & 0.61 & 0.68 \\
\hline $\mathrm{CH}_{2} \mathrm{Cl}_{2}$ & 7.45 & -0.84 & 0.00104 & 1400 & 22 & 10 & -0.80 & 0.17 & 4.88 & 1.08 & 0.94 & 1.00 \\
\hline \multirow[t]{2}{*}{$\mathrm{CH}_{3} \mathrm{CN}$} & 6.76 & -1.00 & 0.0021 & 700 & 17 & 11 & -0.99 & 0.18 & 4.14 & 1.08 & 0.85 & 0.92 \\
\hline & $4 d$ & $5 d$ & $5 d / 4 d$ & $5 d$ & $5 d$ & $6 d$ & 7d & $7 d / 6 d$ & 7d & $7 d$ & $7 d / 5 d$ & $7 d / 5 d$ \\
\hline $\mathrm{C}_{6} \mathrm{H}_{12}$ & 42 & 0.22 & 0.85 & 0.04 & - & 40 & 0.39 & 0.98 & 0.005 & - & 0.35 & - \\
\hline EtOAc & 40 & -0.40 & 0.24 & 0.75 & 0.20 & 39 & -0.35 & 0.94 & 0.016 & 0.015 & 0.64 & 0.86 \\
\hline THF & 39 & -0.47 & 0.08 & 2.9 & 0.44 & 38 & -0.42 & 0.93 & 0.02 & 0.018 & 0.83 & 1.07 \\
\hline $\mathrm{CH}_{2} \mathrm{Cl}_{2}$ & 31 & -0.51 & 0.04 & 7.8 & 0.75 & 30 & -0.47 & 0.92 & 0.03 & 0.025 & 0.92 & 1.13 \\
\hline $\mathrm{CH}_{3} \mathrm{CN}$ & 25 & -0.67 & 0.03 & 13 & 1.2 & 41 & -0.66 & 0.92 & 0.02 & 0.026 & 1.08 & 1.28 \\
\hline
\end{tabular}
solvents

The data of compounds $4 \mathbf{a}, \mathbf{5 a}, \mathbf{6 a}$ and $7 \mathbf{a}$ were abstracted from Ref. 14.

${ }^{a}$ Measured by a picasecond dynamic apparatus (Ref. 29); all others by a Hitachi U-3310 spectrophotometer.

${ }^{\mathrm{b}}$ Estimated by the difference of lifetimes, otherwise calculated by relative luminescence quantum yields. 


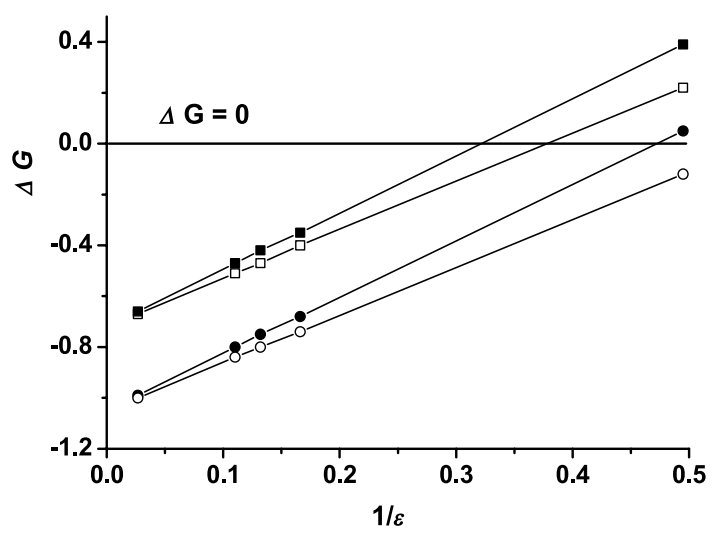

Figure 3. Linear plots of the free energy of ET $(\Delta G)$ versus the reciprocal of solvent dielectric constant $(\varepsilon)$ for compounds $\mathbf{5 c}(\bigcirc), \mathbf{7 c}(\mathbf{O}), \mathbf{5 d}(\square)$ and $7 \mathbf{d}(\boldsymbol{\square})$, respectively. Points below the line of $\Delta G=0$ indicate exothermic ET processes.

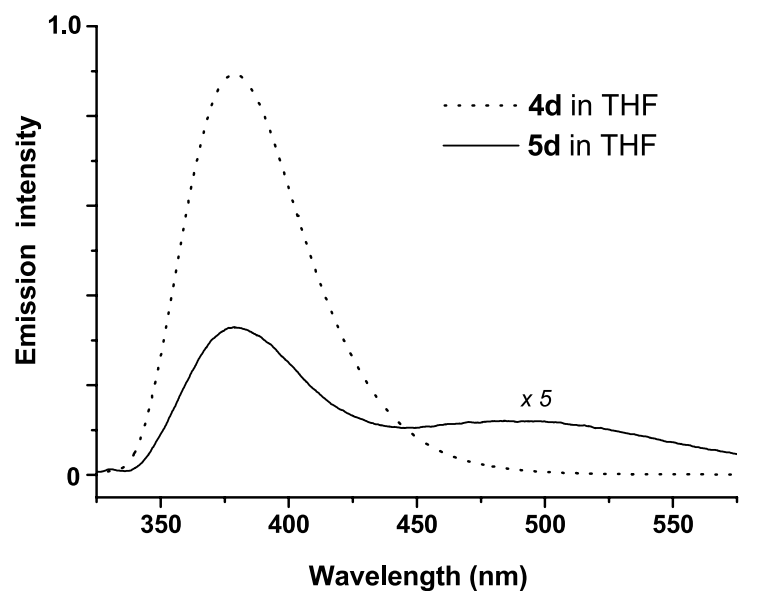

Figure 4. The fluorescence spectra of compounds $\mathbf{4 d}$ (dotted line) and $\mathbf{5 d}$ (solid line) in THF. The quenching of fluorescence $(378 \mathrm{~nm})$ on $\mathbf{5 d}$ is apparent by the reduction of emission intensity. A broad band appeared on the right side $(495 \mathrm{~nm})$ originating from the emission of charges-separated species (CT band).

low quantum yields. According to Marcus formulation, the energy gap of CT emission is related to the barrier of nuclear reorganization $(\lambda)$ during the ET processes. In the case of $\mathbf{5 d}$ in THF, the value of $\lambda$ can be deduced by the following relationship

$\lambda=\Delta G+E_{00}-h \nu_{\mathrm{CT}}$

Taking the data of $\Delta G$ and $E_{00}$ listed in Tables 1 and 2, $\lambda$ was then deduced to be, for example, $\sim 0.75 \mathrm{eV}$ in THF.

The rate constant for a nonadiabatic ET process can be expressed by Fermi's golden rule:

$k_{\mathrm{et}}=\frac{2 \pi}{\hbar}\left|H_{\mathrm{el}}\right|^{2} \mathrm{FC}$

where FC is the Franck-Condon factor, that is, the sum of products of overlap integrals of the vibrational and solvent wave functions of the reactants with those of the products. These factors are weighted for the Boltzmann population of all vibrational energy levels. In the high-temperature limit, Marcus has provided the following expression, which involves an electron-coupling matrix element $\left|H_{\mathrm{el}}\right|$ :

$k_{\mathrm{et}}=\frac{2 \pi}{\left(4 \pi \lambda k_{\mathrm{B}} T\right)^{1 / 2} \hbar}\left|H_{\mathrm{el}}\right|^{2} \exp \left[\frac{-(\Delta G+\lambda)^{2}}{4 \lambda k_{\mathrm{B}} T}\right]$

The value of $H_{\mathrm{el}}$ can be deduced from $\Delta G, \lambda$, and $k_{\mathrm{et}}$, and can further, be used as a criteria for judging the effectiveness of the $\sigma$-spacer group as a modulator for ET dynamics according to a superexchange mechanism. ${ }^{24}$ Figure 5 reveals the plots of $\log k_{\text {et }}$ versus $\Delta G$ based on all experimentally available data points of compounds $\mathbf{5}$ and 7 bearing three kinds of substituents $-\mathrm{H}(\mathbf{a}),-\mathrm{OCH}_{3}(\mathbf{c})$, and $-\mathrm{Ph}$ (d). Note that the fluorescence intensity of bromosubstituted derivatives (b) was too weak to have a reliable value. For the purpose of comparison a simulated curve (Eq. 4) for $\mathbf{5 d}$ in dichloromethane is plotted and shown in Figure 5. Two noteworthy features can be pointed out from the scattering pattern of data points depicted in Figure 5: (1) the ET rates of $\mathbf{5 d}$ and $\mathbf{7 d}$ are slower than the corresponding ones of 5a,c and 7a,c by approximately two orders of magnitude; and (2) the ET rates of all compounds in cyclohexane seem to be substantially faster than what were expected. As shown in the plots of Figure 3, the estimated free energy of ET in nonpolar solvents such as cyclohexane is either greater or close to zero. Accordingly, the rates of ET in such solvents (with $\Delta G \sim 0$ ) are expected to be substantially slower than those in polar solvents (cf. $\Delta G \sim-0.4 \mathrm{eV}$ as shown in Fig. 5). The unexpected high rate of fluorescence quenching in nonpolar solvents is intriguing and may be ascribed to the competing processes associated with electronic energy transfer. Although, the absorption wavelength of acceptor is apparently shorter than the emission wavelength of donor, processes of this kind proceeded in high electronically excited state have been known previously. ${ }^{25}$ In polar solvents the comparatively slow rate of energy transfer is overshadowed by the faster rate of ET process and is likely to be ignored.

Another salient feature is regarding the slow ET rate for $\mathbf{5 d}$ and 7d, which may be rationalized by a mismatch of orbital symmetry between donor and acceptor. The magnitude of

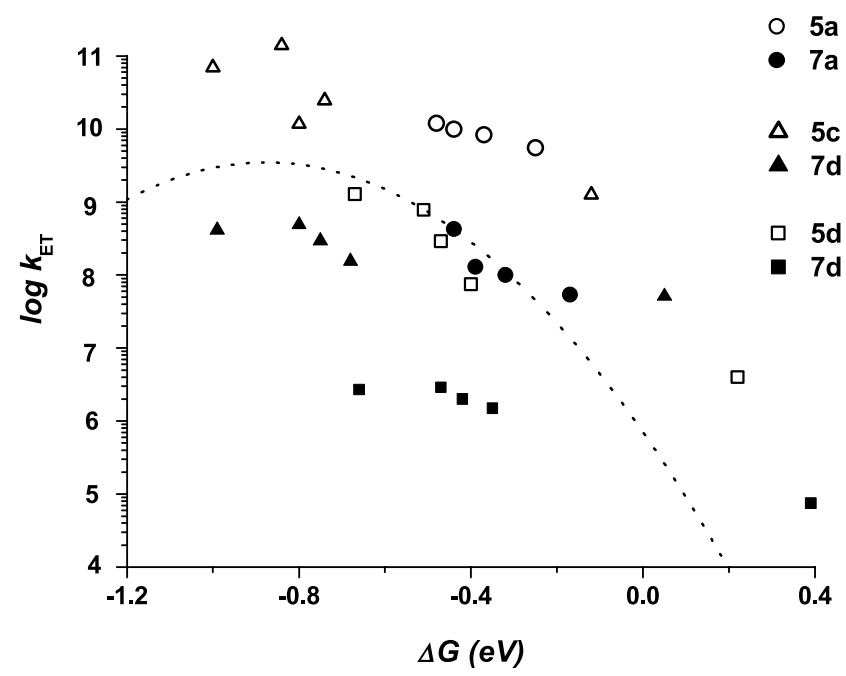

Figure 5. Plots of $\log k_{\mathrm{ET}}$ versus $\Delta G$ of compounds 5a $(\bigcirc), \mathbf{5 d}(\square), 7 \mathbf{a}$ $(\mathbf{O}), 7 \mathbf{c}(\Delta)$, and 7d ( $\square)$ in different solvents. The ET rates of $5 \mathbf{a}$ and $7 \mathbf{a}$ are faster $\left(\sim 10^{2}\right)$ than the corresponding rates of $\mathbf{5 d}$ and $\mathbf{7 d}$. A simulated curve according to Eq. 4 for $\mathbf{5 d}$ in $\operatorname{THF}(. .$.$) is drawn as a reference.$ 
electronic coupling between donor and acceptor depends upon the degree of superexchange interactions, the strength of which relies not only on the relative orientation between the donor and acceptor, but also on the corresponding geometry of spacer group. ${ }^{24}$ The all-trans $\sigma$-array is known to be suitable for modulating electronic interactions. ${ }^{26,27}$ In the structure of $\mathbf{5 c}$ (Fig. 1), it is clear that the $\pi$-face of naphthalene (D) is held rigidly and parallel to the $\pi$-face of ethylene dicarboxylate (A). Similar geometry is maintained in the bromo and methoxy substituted derivatives, that is, $\mathbf{5 b}, \mathbf{c}$ and $\mathbf{7 b}, \mathbf{c}$, as evidenced by the high similarity among their absorption spectra. However, the situation for the diphenyl substituted derivatives such as $\mathbf{5 d}$ and $\mathbf{7 d}$ is rather different, in that the $\pi$-orbitals of naphthalene are perturbed by the free-rotating phenyl groups. Support of this viewpoint is rendered by the absorption spectral features of $\mathbf{5 d}$ and 7d, which are distinctively different from those of 5a-c (not shown here). Likewise, a significant Stokes' shift is observed on their emissions. The spectral difference indicates the presence of conformational variations in both ground and excited states. We thus, tentatively propose that the non-planar conformation of naphthalene chromophores of $\mathbf{5 d}$ and 7d reduce the degree of electron coupling between $\mathrm{D}$ and $\mathrm{A}$, and consequently retard the rate of ET processes.

The value of electronic coupling element $H_{\mathrm{el}}$ is a function of D-A distance and orientation, as well as the bonding nature ( $\sigma$ or $\pi$ ) and geometry of the spacer. As a trend with similar structures, its value decreases exponentially with respect to the edge-to-edge distance $(d-2 r)$ between $\mathrm{D}$ and $\mathrm{A}$ expressed as

$$
H_{\mathrm{el}}=H_{\mathrm{el}}^{0} \exp \left[-\beta^{0}(d-2 r)\right]=H_{\mathrm{el}}^{0} \exp [-n \beta]
$$

where $H_{\mathrm{el}}^{0}$ is a value at contact distance $2 r$ for $\mathrm{D}$ and $\mathrm{A}$, and $\beta^{0}$ is an attenuation coefficient. The value of $H_{\mathrm{el}}$ usually is rather difficult to measure accurately. Empirically, the distance-dependence of ET rate in a specific solvent may be alternatively expressed by the number of $\sigma$-bonds $(n)$ separating $\mathrm{D}$ and $\mathrm{A}$ :

$k_{\mathrm{ET}}=k_{0} \exp \left(-2 n \beta^{\prime}\right)$

McConnell has calculated the distance dependence of electronic coupling in a series of $\alpha, \omega$-diphenylalkanes and found the value of $\beta^{\prime}$ to be ca. $2.5 .^{28}$ Paddon-Row et al. have measured the ET rates across a series of fused norbornadiene skeletons. They found out the value of $\beta^{\prime}$ to be in a range of $0.4-0.63$ depending on the solvents. ${ }^{27}$ These values complied well with that estimated by Hoffmann, ${ }^{26}$ and were much smaller than what were predicted by McConnell. From the rate constants listed in Table 2, the value of $\beta^{\prime}$ can be deduced via comparisons between compounds 5 (6 $\sigma$-bonds between D and A) and 7 ( $9 \sigma$-bonds). For example, the $\beta$ value derived from $\mathbf{5 a} / 7 \mathbf{a}$ in THF was 0.72 in THF, whereas those derived from $\mathbf{5 c / 7} \mathbf{c}$ and $\mathbf{5 d} / \mathbf{7 d}$ were 0.61 and 0.83 , respectively, (Table 2 ). It should be noted that these numbers were neither corrected for distance dependence of the Franck-Condon factor in Eq. 3, nor the conformational variations between the structures of 5 and 7. As depicted by molecular modeling, a change of bending angles between the $\pi$-facial planes of $\mathrm{D}$ and $\mathrm{A}$ appears to be $60^{\circ}$ in $\mathbf{5}$ (see Fig. 1) and $0^{\circ}$ in 7.
Precise estimation on the electronic coupling element $H_{\mathrm{el}}$ remains a difficult task. According to Eq. 2 the value of $\lambda$ can be estimated from the CT emission. It can be divided into two parts, that is, an internal part $\lambda_{i}$ and a solvent dependent part $\lambda_{\mathrm{s}}$. The value of $\lambda_{\mathrm{s}}$ can be estimated by

$\lambda_{\mathrm{s}}=e^{2}\left(1 / r_{\mathrm{D}}^{+}+1 / r_{\mathrm{A}}^{-}-1 / d\right)\left(1 / n^{2}-1 / \varepsilon\right)$

where $n$ is the refractive index of the solvent. The value $\lambda_{i}$ can then be obtained from $\lambda$ (Eq. 2) and $\lambda_{\mathrm{s}}$, and is presumably solvent independent. A reasonable estimation on $\lambda_{\mathrm{i}}$ was in the range of $0.10-0.20 \mathrm{eV}$. This value was taken for the calculation of $H_{\mathrm{el}}$ by Eq. 4, and the results were listed in Table 2. Apparently, $H_{\mathrm{el}}$ of $<10 \mathrm{~cm}^{-1}$ clearly indicate a weak coupling and hence, a nonadiabatic ET process in all cases applied in this study. The averaged $\beta$ value for these ladder-shaped spacers was thus, estimated to be about 1.0.

\section{Conclusion}

In conclusion, the rates of electron transfer were measured across two types of spacer groups, that is, $\mathbf{1}$ and $\mathbf{2}$, where substituted naphthalene acted as the electron donor and ethylene-1,2-dicarboxylate as the acceptor. The methoxyl substituents resonate effectively with the aromatic $\pi$-system, therefore, enrich the electron density of the donor group. Their ET rates became faster in all solvents than the one without methoxy substituents. On the contrary, the presence of phenyl substituents retarded the rates of ET as judged from the same $\Delta G$ values. The conformational flexibility of phenyl substituents seem to perturb the wellaligned symmetry relationship between $\mathrm{D}$ and $\mathrm{A}$, resulting in a reduction of effective electronic coupling. Furthermore, the free-rotated phenyl substituents render a much wider Stokes shifts, as well as a substantial band broadening in the emission spectra.

The free energies of ET were deduced from redox potentials of both $\mathrm{D}$ and $\mathrm{A}$ and the $0-0$ absorption of $\mathrm{D}$. The reorganization energy $\lambda$ was estimated according to the charge transfer emission of $\mathbf{5 d}$ (Fig. 4) by Eq. 2. Accordingly, electronic coupling element $H_{\mathrm{el}}$ was deduced from $\Delta G$ and $\lambda$. Comparing the $H_{\mathrm{el}}$ values of systems 1 and $\mathbf{2}$, the exponential decaying parameter $\beta$ were computed according to the relationship of Eq. 5. The values ranging from 0.6 to 0.9 were not much deviated from analogous cases published in the literatures. The values reveal the nature of these linear ladder-shaped oligonorbornyl spacer groups using as ET modulator, of which the choice is crucial for a proper design of molecular devices.

\section{Experimental}

\subsection{General}

Infrared spectra were recorded on a Perkin-Elmer 682 infrared spectrophotometer. Elemental analyses were obtained on a Perkin-Elmer $2400 \mathrm{CHN}$ instrument. Melting points were measured with a Thomas-Hoover mp apparatus and are uncorrected. ${ }^{1} \mathrm{H}$ and ${ }^{13} \mathrm{C}$ spectra were obtained on a Bruker APX-400 spectrometer. Mass spectra were carried 
out on a VG70-250S spectrometer. Cyclic voltammetry measurements were performed using a voltammetric analyzer and a glassy-carbon working electrode in acetonitrile containing $0.1 \mathrm{M}$ tetra- $n$-butylammonium tetrafluoroborate as a supporting electrolyte. Solvents were all of spectragrade quality. Samples were degassed by three freeze-pump-thaw cycles in vacuo.

Steady-state absorption and emission spectra were recorded by a Hitachi (U-3310) spectrophotometer and an Edinburgh (FS920) fluorimeter, respectively. Details of picosecond dynamical measurements have been elaborated in the previous report. ${ }^{29}$

4.1.1. 15,16-Dibromoheptacyclo $\left[10.8 .1 .1^{4,7} \cdot 0^{3,8} \cdot 0^{2,9}\right.$. $\left.0^{11,20} .0^{13,18}\right]$ docosa-5,11,13,15,-17,19-hexene (4b). A two-neck round bottom flask, fitted with a condenser and a nitrogen inlet-outlet, was filled with a solution of compound $1(1.3 \mathrm{~g}, 7.0 \mathrm{mmol})$ in freshly distilled DMF $(88 \mathrm{~mL})$. To it was added $\alpha, \alpha, \alpha^{\prime}, \alpha^{\prime}$-hexabromo- $o$-xylene $(4.5 \mathrm{~g}, 7.7 \mathrm{mmol})$, followed by sodium iodide $(7.0 \mathrm{~g}$, $47 \mathrm{mmol}$ ) in a nitrogen atmosphere. The resulted solution was heated to $60-70{ }^{\circ} \mathrm{C}$ for $20 \mathrm{~h}$, then was poured slowly into an aqueous solution $(350 \mathrm{~mL})$ of sodium bisulfide $(5 \mathrm{~g})$. The mixture was extracted three times with methylene chloride. The combined organic phase was dried over anhydrous magnesium sulfate, and concentrated in vacuo. The product was purified by passing through a silica gel chromatographic column eluted with hexane/methylene chloride (5:1) to yield white solids (1.9 g, 62\%), mp 223.4-224.4 ${ }^{\circ} \mathrm{C}$. IR (KBr): 3053, 2970, 2955, 1638, 1619, 1579, 1559, 1466, 1400, 1323, 1273, 1261, 1209, 1190, 1101, 947, 928, 898, 885, $703 \mathrm{~cm}^{-1} ;{ }^{1} \mathrm{H}$ NMR (400 MHz, $\left.\mathrm{CDCl}_{3}\right): \delta 7.99(\mathrm{~s}, 2 \mathrm{H}), 7.38(\mathrm{~s}, 2 \mathrm{H}), 6.01(\mathrm{~s}, 2 \mathrm{H}), 3.26(\mathrm{~s}$, 2H), $2.68(\mathrm{~s}, 2 \mathrm{H}), 2.44(\mathrm{~d}, 1 \mathrm{H}, J=10 \mathrm{~Hz}), 1.72(\mathrm{~d}, 1 \mathrm{H}, J=$ $10 \mathrm{~Hz}), 1.57(\mathrm{~m}, 3 \mathrm{H}), 1.55(\mathrm{~s}, 2 \mathrm{H}), 1.18(\mathrm{~d}, 1 \mathrm{H}, J=9 \mathrm{~Hz})$; ${ }^{13} \mathrm{C}$ NMR $\left(100 \mathrm{MHz} \mathrm{CDCl}_{3}\right): \delta$ 148.6, 136.4, 133.0, 132.4, 120.9, 118.0, 46.4, 44.8, 42.7, 42.4, 42.3, 40.3; MS (EI, $70 \mathrm{eV}): \mathrm{m} / \mathrm{z}(\%) 442\left(\mathrm{M}^{+}, 100\right), 376(54), 323(15), 243$ (15), 163 (15). Anal. Calcd for $\mathrm{C}_{22} \mathrm{H}_{18} \mathrm{Br}_{2}$ : C, 59.76\%; $\mathrm{H}$, $4.10 \%$. Found: C, $60.07 \%, \mathrm{H}, 4.36 \%$.

4.1.2. 15,16-Dimethoxyheptacyclo $\left[10.8 \cdot 1.1^{4,7} \cdot 0^{3,8} \cdot 0^{2,9}\right.$. $0^{11,20} .0^{13,18}$ ]docosa-5,11,13,-15,17,19-hexene (4c). A twoneck round bottom flask, fitted with a condenser and a nitrogen inlet-outlet, was filled with a solution of compound 1 (1.3 g, $7.0 \mathrm{mmol})$ in freshly distilled DMF (65 mL). To it was added $\alpha, \alpha, \alpha^{\prime}, \alpha^{\prime}$-hexabromo-4,5-di-methoxy-o-xylene $(3.7 \mathrm{~g}, 7.7 \mathrm{mmol})$, followed by sodium iodide $(7.0 \mathrm{~g}$, $47 \mathrm{mmol})$ in a nitrogen atmosphere. The resulted solution was heated to $60-70{ }^{\circ} \mathrm{C}$ for $20 \mathrm{~h}$, then was poured slowly into an aqueous solution $(350 \mathrm{~mL})$ of sodium bisulfide $(5 \mathrm{~g})$. The yellow precipitates were filtered and dried in vacuo. It was purified by passing through a silica gel chromatographic column eluted with hexane/ethyl acetate $(6: 1)$ to yield white solids $(1.6 \mathrm{~g}, 68 \%), \mathrm{mp} 198.6-199.8^{\circ} \mathrm{C}$. IR (KBr): 3011, 2957, 2926, 1620, 1507, 1460, 1427, 1248, 1144, 1006, 879, 832, $714 \mathrm{~cm}^{-1}$; ${ }^{1} \mathrm{H}$ NMR $(400 \mathrm{MHz}$, $\left.\mathrm{CDCl}_{3}\right): \delta 7.38(\mathrm{~s}, 2 \mathrm{H}), 7.05(\mathrm{~s}, 2 \mathrm{H}), 6.01(\mathrm{~s}, 2 \mathrm{H}), 3.95(\mathrm{~s}$, $6 \mathrm{H}), 3.23(\mathrm{~s}, 2 \mathrm{H}), 2.67(\mathrm{~s}, 2 \mathrm{H}), 2.22(\mathrm{~d}, 1 \mathrm{H}, J=9 \mathrm{~Hz}), 1.71$ $(\mathrm{d}, 1 \mathrm{H}, J=9 \mathrm{~Hz}), 1.52-1.57(\mathrm{~m}, 5 \mathrm{H}), 1.17(\mathrm{~d}, 1 \mathrm{H}, J=7 \mathrm{~Hz})$; ${ }^{13} \mathrm{C}$ NMR $\left(100 \mathrm{MHz} \mathrm{CDCl}_{3}\right): \delta 148.8,145.2,136.1,128.0$, 117.6, 55.1, 46.1, 44.5, 42.7, 42.6, 42.1, 40.1; MS (EI,
$70 \mathrm{eV}): \mathrm{m} / \mathrm{z}(\%) 344\left(\mathrm{M}^{+}, 100\right), 278$ (29), 226 (39), 195 (7), 165 (11). Anal. Calcd for $\mathrm{C}_{24} \mathrm{H}_{24} \mathrm{O}_{2}$ : C, 83.69\%; H, 7.02\%. Found: C, $83.49 \%, \mathrm{H}, 7.34 \%$.

4.1.3. 15,16-Diphenylheptacyclo $\left[10.8 \cdot 1.1^{4,7} \cdot 0^{3,8} .0^{2,9}\right.$. $\left.0^{11,20} .0^{13,18}\right]$ docosa-5,11,13,15,-17,19-hexene (4d). A three-neck round bottom flask, fitted with a condenser and a nitrogen inlet-outlet, was filled with a solution of compound $4 \mathbf{b}(1.5 \mathrm{~g}, 3.4 \mathrm{mmol})$ in freshly distilled DMF $(100 \mathrm{~mL})$. To it under a nitrogen atmosphere was added tetrakis(triphenylphosphine)palladium $(0) \quad(0.2 \mathrm{~g}$, $0.17 \mathrm{mmol})$, followed by phenyboronic acid $(0.9 \mathrm{~g}$, $7.5 \mathrm{mmol})$ and a potassium phosphate solution $(2 \mathrm{~N}$, $20 \mathrm{~mL}$ ). The resulted mixture was heated to reflux for $72 \mathrm{~h}$, then was allowed to cool. It was extracted three times with methylene chloride. The combined organic phase was dried over anhydrous magnesium sulfate, and concentrated in vacuo. The product was purified by passing through a silica gel chromatographic column eluted with hexane/ methylene chloride $(5: 1)$ to form colorless solids $(0.17 \mathrm{~g}$, $11 \%$ ), mp 238.6-239.8 ${ }^{\circ} \mathrm{C}$. IR (KBr): 3021, 2965, 2921, 1653, 1637, 1474, 1458, 1324, 1209, 1187, 1071, 996, 946, 902, 770, 708, $702 \mathrm{~cm}^{-1} ;{ }^{1} \mathrm{H}$ NMR (400 MHz, $\left.\mathrm{CDCl}_{3}\right): \delta$ $7.77(\mathrm{~s}, 2 \mathrm{H}), 7.55(\mathrm{~s}, 2 \mathrm{H}), 7.16-7.24(\mathrm{~m}, 10 \mathrm{H}), 6.02(\mathrm{~s}, 2 \mathrm{H})$, 3.30 (s, 2H), 2.69 (s, 2H), 2.27 (d, 1H, J=10 Hz), 1.77 (d, $1 \mathrm{H}, J=10 \mathrm{~Hz}), 1.61(\mathrm{~s}, 2 \mathrm{H}), 1.60(\mathrm{~d}, 1 \mathrm{H}, J=9 \mathrm{~Hz}), 1.57(\mathrm{~s}$, $2 \mathrm{H}), 1.18(\mathrm{~d}, 1 \mathrm{H}, J=9 \mathrm{~Hz}) ;{ }^{13} \mathrm{C} \mathrm{NMR}\left(100 \mathrm{MHz} \mathrm{CDCl}_{3}\right): \delta$ $147.2,141.8,138.0,135.8,132.0,130.0,129.3,127.8$, 126.3, 118.3, 46.0, 44.3, 42.2, 42.0, 40.0; MS (EI, $70 \mathrm{eV})$ : $\mathrm{m} / \mathrm{z}(\%) 436\left(\mathrm{M}^{+}, 100\right), 370(45), 317$ (47), 241 (15), 165 (3).

4.1.4. 15,16-Dibromo-6,7-dicarbomethoxyoctacyclo$\left[10.10 .1 .1^{4,9} \cdot 0^{2,11} \cdot 0^{3,10} \cdot 0^{5,8} \cdot 0^{13,22}-.0^{15,20}\right]$ tetracosa-6,13, $\mathbf{1 5 , 1 7 , 1 9 , 2 1 - h e x e n e ~ ( 5 b ) . ~ C o m p o u n d ~} \mathbf{5 b}$ was collected in $78 \%$ yield following a similar procedure to that of $\mathbf{5 c}$. Physical data of 5b: $\mathrm{mp} 254-256^{\circ} \mathrm{C}$. IR (KBr): 3011, 2954, 2925, 1738, 1717, 1638, 1629, 1463, 1433, 1402, 1267, $1232,1197,1136,1120,1101,1050,929,896 \mathrm{~cm}^{-1} ;{ }^{1} \mathrm{H}$ NMR (400 MHz, CDCl 3 ): $\delta 8.01(\mathrm{~s}, 2 \mathrm{H}), 7.40(\mathrm{~s}, 2 \mathrm{H}), 3.79$ (s, 6H), $3.27(\mathrm{~s}, 2 \mathrm{H}), 2.62(\mathrm{~s}, 2 \mathrm{H}), 2.38(\mathrm{~d}, 1 \mathrm{H}, J=10 \mathrm{~Hz})$, $2.20(\mathrm{~s}, 2 \mathrm{H}), 1.74-1.77(\mathrm{~m}, 4 \mathrm{H}), 1.62-1.65(\mathrm{~m}, 2 \mathrm{H}), 1.29(\mathrm{~d}$, $1 \mathrm{H}, J=10 \mathrm{~Hz}) ;{ }^{13} \mathrm{C} \mathrm{NMR}\left(100 \mathrm{MHz}, \mathrm{CDCl}_{3}\right): \delta 161.5$, $147.3,142.0,132.5,131.8,120.5,117.5,51.8,45.6,45.6$, 43.7, 42.9, 41.8, 36.8, 26.0; MS (EI, $70 \mathrm{eV}): \mathrm{m} / \mathrm{z}(\%) 584$ $\left(\mathrm{M}^{+}, 100\right), 553$ (9), 350 (41), 323 (18), 243 (27), 163 (26). Anal. Calcd for $\mathrm{C}_{28} \mathrm{H}_{24} \mathrm{Br}_{2} \mathrm{O}_{4}$ : C, $57.56 \% ; \mathrm{H}, 4.14 \%$. Found: C, $57.55 \%, \mathrm{H}, 4.11 \%$.

4.1.5. 6,7-Dicarbomethoxy-15,16-dimethoxyoctacyclo$\left[10.10 .1 .1^{4,9} \cdot 0^{2,11} \cdot 0^{3,10} \cdot 0^{5,8} \cdot 0^{13,22} \cdot 0^{15,20}\right]$ tetracosa-6,13, $15,17,19,21$-hexene $(5 \mathrm{c})$. To a two-neck round bottom flask, fitted with a condenser and a nitrogen inlet-outlet, were added of compound $\mathbf{4 c}(100 \mathrm{mg}, 0.3 \mathrm{mmol})$, dimethyl acetylenedicarboxylate $(0.04 \mathrm{~mL}, 0.3 \mathrm{mmol})$, and a catalytic amount of $\mathrm{RuH}_{2} \mathrm{CO}\left(\mathrm{PPh}_{3}\right)_{3}$ in freshly distilled benzene $(10 \mathrm{~mL})$. The resulted solution was stirred with a magnetic bar for $15 \mathrm{~min}$ at ambient temperature, then was heated to reflux for $24 \mathrm{~h}$. The solvent was evaporated in vacuo, and the product was purified by passing through a silica gel chromatographic column eluted with hexane/ethyl acetate (6:1) to yield white solids (121 mg, 83\%), mp 214$215^{\circ} \mathrm{C}$. IR (KBr): 3007, 2952, 1722, 1627, 1508, 1464, 
1433, 1318, 1251, 1195, 1147, 1050, 1011, 887, $743 \mathrm{~cm}^{-1}$; ${ }^{1} \mathrm{H}$ NMR $\left(400 \mathrm{MHz}, \mathrm{CDCl}_{3}\right): \delta 7.40(\mathrm{~s}, 2 \mathrm{H}), 7.07(\mathrm{~s}, 2 \mathrm{H})$, $3.97(\mathrm{~s}, 6 \mathrm{H}), 3.78(\mathrm{~s}, 6 \mathrm{H}), 3.24(\mathrm{~s}, 2 \mathrm{H}), 2.62(\mathrm{~s}, 2 \mathrm{H}), 2.36(\mathrm{~d}$, $1 \mathrm{H}, J=10 \mathrm{~Hz}), 2.19(\mathrm{~s}, 2 \mathrm{H}), 1.73-1.76(\mathrm{~m}, 5 \mathrm{H}), 1.65(\mathrm{~d}, 1 \mathrm{H}$, $J=11 \mathrm{~Hz}), 1.27(\mathrm{~d}, 1 \mathrm{H}, J=11 \mathrm{~Hz}) ;{ }^{13} \mathrm{C}$ NMR $(100 \mathrm{MHz}$, $\left.\mathrm{CDCl}_{3}\right): \delta 161.8,148.8,144.5,142.3,128.1,117.6,107.0$, 56.1, 52.0, 46.0, 45.9, 44.4, 43.3, 42.4, 37.0, 26.2; MS (EI, $70 \mathrm{eV}): m / z(\%) 486\left(\mathrm{M}^{+}, 100\right), 455$ (5), 277 (4), 252 (16), 226 (26), 165.1 (4). Anal. Calcd for $\mathrm{C}_{30} \mathrm{H}_{30} \mathrm{O}_{6}: \mathrm{C}, 74.06 \%$; H, $6.21 \%$. Found: C, $73.84 \%$, H, 5.97\%.

The crystal structure of 5c was solved on a Nonius diffractometer using the $\theta / 2 \theta$ scan method. It was monoclinic in space group $C 2 / c$ with $a=30.929(7) \AA, b=$ 8.700(1) $\mathrm{A}, \quad$ and $c=21.194(3) \AA, \quad \alpha=90^{\circ}, \quad \beta=$ $113.466(14)^{\circ}, \gamma=90^{\circ}$. Crystallographic data has been deposited with the Cambridge Crystallographic Data Centre as supplementary publication numbers CCDC 266303. Copies of the data can be obtained, free of charge, on application to CCDC, 12 Union Road, Cambridge CB2 1EZ, UK [fax: 144 (0)1223 336033 or e-mail: deposit@ccdc.cam. ac.uk].

\subsubsection{6,7-Dicarbomethoxy-15,16-diphenyloctacyclo-} $\left[10.10 .1 .1^{4,9} \cdot 0^{2,11} .0^{3,10} \cdot 0^{5,8} \cdot 0^{13,22} \cdot 0^{15,20}\right]$ tetracosa-6,13, 15,17,19,21-hexene (5d). Compound 5d was collected in $78 \%$ yield following a similar procedure to that of $\mathbf{5 c}$. Physical data of 5d: $\mathrm{mp} 217.5-219^{\circ} \mathrm{C}$. IR (KBr): 3053 , 2965, 2952, 1738, 1720, 1638, 1629, 1474, 1437, 1322, 1298, 1282, 1265, 1228, 1217, 1197, 1133, 1121, 1051, 947, 905, 770, 748, $700 \mathrm{~cm}^{-1} ;{ }^{1} \mathrm{H}$ NMR (400 MHz, $\left.\mathrm{CDCl}_{3}\right): \delta$ $7.77(\mathrm{~s}, 2 \mathrm{H}), 7.55(\mathrm{~s}, 2 \mathrm{H}), 7.15-7.22(\mathrm{~m}, 10 \mathrm{H}), 3.76(\mathrm{~s}, 6 \mathrm{H})$, $3.28(\mathrm{~s}, 2 \mathrm{H}), 2.60(\mathrm{~s}, 2 \mathrm{H}), 2.37(\mathrm{~d}, 1 \mathrm{H}, J=10 \mathrm{~Hz}), 2.18(\mathrm{~s}$, 2H), 1.76-1.77 (d, 5H), $1.62(\mathrm{~d}, 1 \mathrm{H}, J=11 \mathrm{~Hz}), 1.26(\mathrm{~d}, 1 \mathrm{H}$, $J=11 \mathrm{~Hz}) ;{ }^{13} \mathrm{C}$ NMR $\left(100 \mathrm{MHz}, \mathrm{CDCl}_{3}\right): \delta 161.5,146.4$, $142.0,141.8,138.1,132.0,130.0,129.3,127.8,126.3$, 118.4, 51.8, 45.7, 44.1, 43.3, 41.9, 36.8, 26.0; MS (EI, $70 \mathrm{eV}): \mathrm{m} / \mathrm{z}(\%) 578.1\left(\mathrm{M}^{+}, 100\right), 547.1$ (4), 344.1 (31), 318.1 (30), 241.1 (5), 165.1 (1). Anal. Calcd for $\mathrm{C}_{40} \mathrm{H}_{34} \mathrm{O}_{4}$ : C, $83.02 \%$; H, 5.92\%. Found: C, $82.78 \%, \mathrm{H}, 6.00 \%$.

4.1.7. 21,22-Dibromodecacyclo[14.10.1.1 $1^{4,13} \cdot 1^{7,10} .0^{2,15}$. $\left.0^{3,14} .0^{5,12} .0^{6,11} .0^{17,26} .0^{19,24}\right]$ hexacosa-8,17,19,21,23,25hexene (6b). A two-neck round bottom flask, fitted with a condenser and a nitrogen inlet-outlet, was filled with a solution of compound $2(1.9 \mathrm{~g}, 7.0 \mathrm{mmol})$ in freshly distilled DMF $(95 \mathrm{~mL})$. To it was added $\alpha, \alpha, \alpha^{\prime}, \alpha^{\prime}$-hexabromo-oxylene ( $4.5 \mathrm{~g}, 7.7 \mathrm{mmol})$, followed by sodium iodide $(7.0 \mathrm{~g}$, $47 \mathrm{mmol})$ in a nitrogen atmosphere. The resulted solution was heated to $60-70^{\circ} \mathrm{C}$ for $20 \mathrm{~h}$, then was poured slowly into an aqueous solution $(350 \mathrm{~mL})$ of sodium bisulfide $(5 \mathrm{~g})$. The mixture was extracted three times with methylene chloride. The combined organic phase was dried over anhydrous magnesium sulfate, and concentrated in vacuo. The product was purified by passing through a silica gel chromatographic column eluted with hexane/methylene chloride (5:1) to yield white solids $(2.2 \mathrm{~g}, 60 \%)$, mp 289$291{ }^{\circ} \mathrm{C}$. IR (KBr): 3048, 2963, 2930, 1631, 1583, 1464, 1402, 1326, 1266, 1225, 1102, 949, 928, 896, $715 \mathrm{~cm}^{-1} ;{ }^{1} \mathrm{H}$ NMR (400 MHz, $\left.\mathrm{CDCl}_{3}\right): \delta 8.01(\mathrm{~s}, 2 \mathrm{H}), 7.38(\mathrm{~s}, 2 \mathrm{H}), 5.93$ $(\mathrm{s}, 2 \mathrm{H}), 3.22(\mathrm{~s}, 2 \mathrm{H}), 2.61(\mathrm{~s}, 2 \mathrm{H}), 2.36(\mathrm{~d}, 1 \mathrm{H}, J=10 \mathrm{~Hz})$, $1.93(\mathrm{~s}, 2 \mathrm{H}), 1.77-1.65(\mathrm{~m}, 4 \mathrm{H}), 1.68(\mathrm{~s}, 2 \mathrm{H}), 1.62(\mathrm{~s}, 2 \mathrm{H})$, $1.38(\mathrm{~s}, 2 \mathrm{H}), 1.35(\mathrm{~s}, 2 \mathrm{H}), 1.16(\mathrm{~d}, 1 \mathrm{H}, J=8.2 \mathrm{~Hz}) ;{ }^{13} \mathrm{C}$
NMR $\left(100 \mathrm{MHz}, \mathrm{CDCl}_{3}\right): \delta 157.9,135.5,132.7,132.0$, 129.0, 127.4, 117.6, 46.0, 44.4, 43.6, 42.6, 41.9, 41.6, 41.7, 40.9, 29.1; MS (EI, $70 \mathrm{eV}): \mathrm{m} / \mathrm{z}(\%) 534\left(\mathrm{M}^{+}, 100\right), 468$ (46), 376 (14), 350 (45), 269 (11), 189 (15), 163 (11). Anal. Calcd for $\mathrm{C}_{29} \mathrm{H}_{26} \mathrm{Br}_{2}$ : C, 65.19\%; H, 4.90\%. Found: C, $65.46 \%, \mathrm{H}, 5.49 \%$.

4.1.8. 21,22-Dimethoxydecacyclo[14.10.1.1 $1^{4,13} \cdot 1^{7,10}$. $\left.0^{2,15} \cdot 0^{3,14} \cdot 0^{5,12} .0^{6,11} \cdot 0^{17,26} \cdot 0^{19,24}\right]$ hexacosa-8,17,19,21,23, 25-hexene (6c). Compound $\mathbf{6 c}$ was collected in $63 \%$ yield according to a similar procedure to the preparation of $\mathbf{6 b}$. Physical data of 6c: $\mathrm{mp}$ 258.5-259.5 ${ }^{\circ} \mathrm{C}$. IR (KBr): 2961, 2921, 1621, 1511, 1464, 1426, 1251, 1144, 1005, 884, $710 \mathrm{~cm}^{-1} ;{ }^{1} \mathrm{H}$ NMR $\left(400 \mathrm{MHz}, \mathrm{CDCl}_{3}\right): \delta 7.35(\mathrm{~s}, 2 \mathrm{H})$, 7.04 (s, 2H), $5.91(\mathrm{~s}, 2 \mathrm{H}), 3.95(\mathrm{~s}, 6 \mathrm{H}), 3.17$ (s, 2H), 2.59 (s, $2 \mathrm{H}), 2.31(\mathrm{~d}, 1 \mathrm{H}, J=10.0 \mathrm{~Hz}), 1.90(\mathrm{~s}, 2 \mathrm{H}), 1.75(\mathrm{~d}, 1 \mathrm{H}, J=$ $9 \mathrm{~Hz}), 1.70-1.65(\mathrm{~m}, 5 \mathrm{H}), 1.66(\mathrm{~s}, 2 \mathrm{H}), 1.32$ (s, 2H), 1.23 (s, $2 \mathrm{H}), 1.14(\mathrm{~d}, 1 \mathrm{H}, J=9 \mathrm{~Hz}) ;{ }^{13} \mathrm{C}$ NMR $\left(100 \mathrm{MHz}, \mathrm{CDCl}_{3}\right): \delta$ $148.5,144.7,135.3,127.8,117.2,106.8,55.8,45.8,44.2$, 44.0, 42.5, 42.1, 41.8, 41.5, 41.4, 40.7, 28.9; MS (EI, $70 \mathrm{eV}): \mathrm{m} / z(\%) 436\left(\mathrm{M}^{+}, 100\right), 370$ (15), 277 (4), 252 (15), 226 (15), 165 (4). Anal. Calcd for $\mathrm{C}_{31} \mathrm{H}_{32} \mathrm{O}_{2}: \mathrm{C}, 85.28 \% ; \mathrm{H}$, $7.39 \%$. Found: C, $85.28 \%, \mathrm{H}, 7.45 \%$.

4.1.9. 21,22-Diphenyldecacyclo[14.10.1.1 $1^{4,13} \cdot 1^{7,10} \cdot 0^{2,15}$. $\left.0^{3,14} .0^{5,12} .0^{6,11} .0^{17,26} \cdot 0^{19,24}\right]$ hexacosa-8,17,19,21,23,25hexene (6d). A three-neck round bottom flask, fitted with a condenser and a nitrogen inlet-outlet, was filled with a solution of compound $\mathbf{6 b}(2.0 \mathrm{~g}, 3.7 \mathrm{mmol})$ in freshly distilled DMF (100 mL). To it under a nitrogen atmosphere was added tetrakis(triphenylphosphine)palladium(0) $(0.22 \mathrm{~g}, 0.185 \mathrm{mmol})$, followed by phenylboronic acid $(1.0 \mathrm{~g}, 8.1 \mathrm{mmol})$ and a potassium phosphate solution $(2 \mathrm{~N}, 20 \mathrm{~mL})$. The resulted mixture was heated to reflux for $72 \mathrm{~h}$, then was allowed to cool. It was extracted three times with methylene chloride. The combined organic phase was dried over anhydrous magnesium sulfate, and concentrated in vacuo. The product was purified by passing through a silica gel chromatographic column eluted with hexane/ methylene chloride $(5: 1)$ to form white solids $(0.20 \mathrm{~g}, 10 \%)$, mp 289-291 ${ }^{\circ} \mathrm{C}$. IR (KBr): 3052, 2960, 2924, 1600, 1476, 1463, 1443, 1420, 1325, 1261, 1071, 949, 903, 770, 760, 747, 700, $567 \mathrm{~cm}^{-1} ;{ }^{1} \mathrm{H}$ NMR (400 MHz, $\left.\mathrm{CDCl}_{3}\right): \delta 7.77(\mathrm{~s}$, $2 \mathrm{H}), 7.56(\mathrm{~s}, 2 \mathrm{H}), 7.20-7.27(\mathrm{~m}, 10 \mathrm{H}), 5.94(\mathrm{~s}, 2 \mathrm{H}), 3.26(\mathrm{~s}$, 2H), $2.61(\mathrm{~s}, 2 \mathrm{H}), 2.40(\mathrm{~d}, 1 \mathrm{H}, J=10 \mathrm{~Hz}), 1.95(\mathrm{~s}, 2 \mathrm{H}), 1.79$ (d, $1 \mathrm{H}, J=9 \mathrm{~Hz}), 1.78-1.72(\mathrm{~m}, 5 \mathrm{H}), 1.72(\mathrm{~s}, 2 \mathrm{H}), 1.39$ (s, $2 \mathrm{H}), 1.38(\mathrm{~s}, 2 \mathrm{H}), 1.15(\mathrm{~d}, 1 \mathrm{H}, J=8.0 \mathrm{~Hz}) ;{ }^{13} \mathrm{C} \mathrm{NMR}$ $\left(100 \mathrm{MHz}, \mathrm{CDCl}_{3}\right): \delta 1147.1,142.1,138.2,135.5,132.2$, $130.3,129.5,128.0,126.5,118.4,46.1,44.5,44.1,42.8$, 42.1, 42.0, 41.8, 41.7, 40.9, 29.2; MS (EI, $70 \mathrm{eV}): \mathrm{m} / \mathrm{z}(\%)$ $528\left(\mathrm{M}^{+}, 100\right), 462$ (11), 370 (5), 344 (30), 318 (15), 241 (5), 165 (1); MS (EI, $70 \mathrm{eV}): m / z(\%) 528\left(\mathrm{M}^{+}, 100\right), 462$ (10), 344 (22), 331 (18), 318 (20).

4.1.10. 9,10-Dibromo-23,24-dicarbomethoxyundecacyclo[16.10.1.1 $1^{4,15} \cdot 1^{21,26} \cdot 0^{2,17} \cdot 0^{3,16} \cdot 0^{5,14} \cdot 0^{7,12} \cdot 0^{19,28} \cdot 0^{20,27}$. $\mathbf{0}^{22,25}$ ]octacosa-5,7,9,11,13,23-hexene (7b). Compound 7b was collected in $78 \%$ yield following a similar procedure to that of 5c. Physical data of 7b: mp 319.5-321.0 ${ }^{\circ} \mathrm{C}$. IR (KBr): 2951, 2927, 1740, 2719, 1627, 1618, 1559, 1435, 1267, 1232, 1197, 1138, 1124, 1100, 1049, 929, 896, $670 \mathrm{~cm}^{-1} ;{ }^{1} \mathrm{H}$ NMR $\left(400 \mathrm{MHz}, \mathrm{CDCl}_{3}\right): \delta 8.0(\mathrm{~s}, 2 \mathrm{H}), 7.38$ (s, 1H), 3.78 (s, 6H), 3.22 (s, 2H), $2.51(\mathrm{~s}, 2 \mathrm{H}), 2.35$ (d, 1H, 
$J=10 \mathrm{~Hz}), 2.10(\mathrm{~s}, 2 \mathrm{H}), 1.58-1.92(\mathrm{~m}, 14 \mathrm{H}), 1.30(\mathrm{~d}, 1 \mathrm{H}$, $J=11 \mathrm{~Hz}) ;{ }^{13} \mathrm{C}$ NMR $\left(100 \mathrm{MHz}, \mathrm{CDCl}_{3}\right): \delta 161.8,147.8$, 142.2 , 132.7, 132.0, 120.6, 117.6, 52.0, 46.0, 45.8, 44.81, 44.2, 43.7, 42.2, 42.0, 41.7, 37.0, 29.2, 26.2; MS (EI, $70 \mathrm{eV}): m / z(\%) 676\left(\mathrm{M}^{+}, 100\right), 645(8), 442(8), 376(9)$, 350 (34), 323 (11), 243 (16), 163 (8). Anal. Calcd for $\mathrm{C}_{35} \mathrm{H}_{32} \mathrm{Br}_{2} \mathrm{O}_{4}$ : C, $62.15 \%$; H, 4.77\%. Found: C, 62.29\%, H, $4.89 \%$.

4.1.11. 23,24-Dicarbomethoxy-9,10-dimethoxyundecacyclo[16.10.1.1 $1^{4,15} \cdot 1^{21,26} \cdot 0^{2,17} \cdot 0^{3,16} \cdot 0^{5,14} .0^{7,12} \cdot 0^{19,28} \cdot 0^{20,27}$. $\left.0^{22,25}\right]$ octacosa-5,7,9,11,13,23-hexene (7c). Compound 7c was collected in $78 \%$ yield following a similar procedure to that of 5c. Physical data of 7c: $\mathrm{mp} 306.5-308.5^{\circ} \mathrm{C}$. IR (KBr): 2953, 2921, 1727, 1625, 1506, 1466, 1430, 1321, $1249,1196,1143,1046,1008,880 \mathrm{~cm}^{-1}$; ${ }^{1} \mathrm{H}$ NMR $\left(400 \mathrm{MHz}, \mathrm{CDCl}_{3}\right): \delta 7.35(\mathrm{~s}, 2 \mathrm{H}), 7.04(\mathrm{~s}, 2 \mathrm{H}), 3.94(\mathrm{~s}$, $6 \mathrm{H}), 3.75(\mathrm{~s}, 6 \mathrm{H}), 3.15(\mathrm{~s}, 2 \mathrm{H}), 2.48(\mathrm{~s}, 2 \mathrm{H}), 2.29(\mathrm{~d}, 1 \mathrm{H}, J=$ $10 \mathrm{~Hz}), 2.07$ (s, 2H), $1.87(\mathrm{~s}, 2 \mathrm{H}), 1.87-1.80(\mathrm{~m}, 2 \mathrm{H}), 1.71$ $(\mathrm{d}, J=10 \mathrm{~Hz}, 1 \mathrm{H}), 1.70(\mathrm{~s}, 2 \mathrm{H}), 1.70-1.69(\mathrm{~m}, 1 \mathrm{H}), 1.58(\mathrm{~s}$, 2H), 1.55 (s, 2H), $1.53(\mathrm{~s}, 2 \mathrm{H}), 1.27(\mathrm{~d}, 1 \mathrm{H}, J=11 \mathrm{~Hz}) ;{ }^{13} \mathrm{C}$ NMR $\left(100 \mathrm{MHz}, \mathrm{CDCl}_{3}\right)$ : $\delta$ 161.2, 148.7, 144.6, 142.1, 127.9, 117.4, 106.9, 55.9, 51.9, 45.9, 45.7, 44.7. 44.1, 44.1, 42.2, 42.2, 41.6, 36.9, 29.0, 26.1; MS (EI, $70 \mathrm{eV}): \mathrm{m} / \mathrm{z}(\%)$ $578\left(\mathrm{M}^{+}, 100\right), 547$ (4), 344 (2), 252 (15), 226 (18), 165 (16). Anal. Calcd for $\mathrm{C}_{37} \mathrm{H}_{38} \mathrm{O}_{6}: \mathrm{C}, 76.79 \% ; \mathrm{H}, 6.62 \%$. Found: C, $76.71 \%, \mathrm{H}, 6.70 \%$.

4.1.12. 23,24-Dicarbomethoxy-9,10-diphenylundecacyclo[16.10.1.1 $1^{4,15} \cdot 1^{21,26} \cdot 0^{2,17} \cdot 0^{3,16} \cdot 0^{5,14} \cdot 0^{7,12} \cdot 0^{19,28} \cdot 0^{20,27}$. $0^{22,25}$ ]octacosa-5,7,9,11,13,23-hexene (7d). Compound 7d was collected in $78 \%$ yield following a similar procedure to that of 5c. Physical data of 7d: mp 294.5-296 ${ }^{\circ} \mathrm{C}$. IR (KBr): 3060, 2950, 2922, 1736, 1719, 1632, 1598, 1474, 1436, 1322, 1267, 1232, 1208, 1198, 1049, 966, 949, 904, 770, $742,697 \mathrm{~cm}^{-1}$; ${ }^{1} \mathrm{H}$ NMR $\left(400 \mathrm{MHz}, \mathrm{CDCl}_{3}\right): \delta 7.76(\mathrm{~s}$, 2H), $7.52(\mathrm{~s}, 2 \mathrm{H}), 7.17-7.19(\mathrm{~m}, 10 \mathrm{H}), 3.76(\mathrm{~s}, 6 \mathrm{H}), 3.22(\mathrm{~s}$, 2H), 2.49 (s, 2H), 2.34 (d, 1H, J=10 Hz), 2.08 (s, 2H), 1.89 (s, 2H), 1.89-1.80 (m, 2H), 1.73-1.70 (m, 2H), 1.70 (s, 2H), $1.59(\mathrm{~s}, 2 \mathrm{H}), 1.56(\mathrm{~s}, 4 \mathrm{H}), 1.27(\mathrm{~d}, 1 \mathrm{H}, J=11 \mathrm{~Hz}) ;{ }^{13} \mathrm{C} \mathrm{NMR}$ $\left(100 \mathrm{MHz}, \mathrm{CDCl}_{3}\right): \delta 161.6,146.7,142.0,141.8,138.0$, $132.0,130.0,129.3,127.8,126.3,118.2,51.8,45.9,45.6$, 44.6, 44.0, 43.9, 42.1, 41.9, 41.5, 36.8, 28.9, 26.0; MS (EI, $70 \mathrm{eV}): m / z(\%) 670\left(\mathrm{M}^{+}, 100\right), 639$ (3), 436 (1), 370 (5), 344 (14), 318 (11), 241 (3).

\section{Acknowledgements}

Supports from Academia Sinica and the National Science Council of Taiwan are gratefully acknowledged.

\section{References and notes}

1. (a) Metzger, R. M. J. Mater. Chem. 2000, 10, 55-62. (b) Scheib, S.; Cava, M. P.; Baldwin, J. W.; Metzger, R. M. J. Org. Chem. 1998, 63, 1198-1204. (c) Aviram, A.; Ratner, M. A. Chem. Phys. Lett. 1974, 29, 277-283.

2. (a) Chen, J.; Reed, M. A.; Rawlett, A. M.; Tour, J. M. Science 1999, 286, 1550-1552. (b) de Silva, A. P.; Gunaratne,
H. Q. N.; Gunnlaugsson, T.; Huxley, A. J. M.; McCoy, C. P.; Rademacher, J. T.; Rice, T. E. Chem. Rev. 1997, 97, 1515-1566.

3. (a) Yu, C. J.; Chong, Y.; Kayyem, J. F.; Gozin, M. J. Org. Chem. 1999, 64, 2070-2079. (b) Lewis, F. D.; Wu, T.; Zhang, Y.; Letsinger, R. L.; Greenfield, S. R.; Wasielewski, M. R. Science 1997, 277, 673-676.

4. (a) Gust, D.; Moore, T. A.; Moore, A. L. Acc. Chem. Res. 1993, 26, 198-205. (b) Roest, M. R.; Verhoeven, J. W.; Schuddeboom, W.; Warman, J. M.; Lawson, J. M.; Paddon-Row, M. N. J. Am. Chem. Soc. 1996, 118, 1762-1768.

5. Boyd, R. W. Nonlinear Optics; Academic: New York, 1992. Prasad, P. N.; Williams, D. J. Introduction to Nonlinear Optical Effects in Molecular and Polymers; Wiley: New York, 1991.

6. (a) Chattoraj, M.; Paulson, B.; Shi, Y.; Closs, G. L.; Levy, D. H. J. Phys. Chem. 1994, 98, 3361-3368. (b) Chattoraj, M.; Bal, B.; Closs, G. L.; Levy, D. H. J. Phys. Chem. 1992, 95, 9666-9673.

7. Balzani, V.; Juris, A.; Venturi, M. Chem. Rev. 1996, 96, 759-834.

8. Zimmerman, H. E.; Goldman, T. D.; Hirzel, T. K.; Schmidt, S. P. J. Org. Chem. 1980, 45, 3933-3951.

9. (a) Tung, C. H.; Zhang, L. P.; Li, Y.; Cao, H.; Tanimoto, Y. J. Am. Chem. Soc. 1997, 119, 5348-5254. (b) Agyin, J. K.; Timberlake, L. D.; Morrison, H. J. Am. Chem. Soc. 1997, 119, 7945-7953.

10. Warrener, R. N. Eur. J. Org. Chem. 2000, 3363-3380.

11. Warrener, R. N.; Pitt, I. G.; Butler, D. N. J. Chem. Soc., Chem. Commun. 1983, 1340-1341.

12. Warrener, R. N.; Abbenante, G.; Kennard, C. H. L. J. Am. Chem. Soc. 1994, 116, 3645-3636.

13. (a) Chiou, N. R.; Chow, T. J.; Chen, C. Y.; Hsu, M. A.; Chen, H. C. Tetrahedron Lett. 2001, 42, 29-31. (b) Chow, T. J.; Hon, Y. S.; Chen, C. Y.; Huang, M. S. Tetrahedron Lett. 1999, 40, 7799-7801.

14. Chen, K.-Y.; Chow, T. J.; Chou, P.-T.; Cheng, Y.-M.; Tsaia, S.-H. Tetrahedron Lett. 2002, 43, 8115-8119.

15. (a) Hieber, W.; Sedlmeier, J. Chem. Ber. 1954, 87, 789. (b) Arnold, D. R.; Trecker, D. J.; Whipple, E. B. J. Am. Chem. Soc. 1965, 87, 2596-2602.

16. (a) Paddon-Row, M. N.; Patney, H. K. Synthesis 1986, 328-330. (b) Cava, M. P.; Deana, A. A.; Muth, K. J. Am. Chem. Soc. 1959, 81, 6458-6460. (c) Mcomie, J. F. W.; Perry, D. H. Synthesis 1973, 416-417.

17. (a) Miyaura, N.; Yanagi, T.; Suzuki, A. Synth. Commun. 1981, 11,513-519. (b) Miyaura, N.; Suzuki, A. Chem. Rev. 1995, 95, 2457-2483.

18. (a) Ahmad, N.; Levison, J. J.; Robinson, S. D.; Uttley, M. G. Inorg. Synth. 1974, 15, 45-64. (b) Kumar, K.; Tepper, R. J.; Zeng, Y.; Zimmt, M. B. J. Org. Chem. 1995, 60, 4051-4066.

19. Platt, J. R. J. Chem. Phys. 1949, 17, 484-495.

20. Jaffĕ, H. H.; Orchin, M. Theory and Applications of Ultraviolet Spectroscopy; Wiley: New York, 1962.

21. (a) Marcus, R. A. J. Chem. Phys. 1965, 43, 679-701. (b) Marcus, R. A. Annu. Rev. Phys. Chem. 1964, 15, 155-196. (c) Marcus, R. A. J. Chem. Phys. 1956, 24, 966-978. (d) Marcus, R. A. Discuss. Faraday Soc. 1960, 29, 21. (e) Marcus, R. A.; Sutin, N. Biochim. Biophys. Acta 1985, 811, 265-322.

22. Oevering, H.; Paddon-Row, M. N.; Heppener, M.; Oliver, A. M.; Cotsaris, E.; Verhoeven, J. A.; Hush, N. S. J. Am. Chem. Soc. 1987, 109, 3258-3269.

23. Chow, T. J.; Chen, H.-C.; Chiu, N.-R.; Chen, C.-Y.; Yu, 
W.-.S.; Cheng, Y.-M.; Cheng, C.-C.; Chang, C.-P.; Chou, P.-T. Tetrahedron 2003, 59, 5719-5730.

24. Siders, P.; Cave, R. J.; Marcus, R. A. J. Chem. Phys. 1984, 81, 5613-5624.

25. Lokan, N.; Paddon-Row, M. N.; Smith, T. A.; Rosa, M. L.; Ghiggino, K. P.; Speiser, S. J. Am. Chem. Soc. 1999, 121, 2917-2919.

26. (a) Hoffmann, R.; Imamura, A.; Hehre, W. J. Am. Chem. Soc.
1968, 90, 1499-1509. (b) Hoffmann, R. Acc. Chem. Res. 1971, 4, 1-9.

27. (a) Paddon-Row, M. N. Acc. Chem. Res. 1994, 27, 18-25. (b) Jordan, K. D.; Paddon-Row, M. N. J. Phys. Chem. 1992, 96, 1188-1196.

28. McConnell, H. M. J. Chem. Phys. 1961, 35, 508-515.

29. Chou, P. T.; Chen, Y. C.; Yu, W. S.; Chou, Y. H.; Wei, C. Y.; Cheng, Y. M. J. Phys. Chem. A 2001, 105, 1731-1740. 